\title{
O USO DOS INSTRUMENTOS DE PERCUSSÃO EM MUSICALIZAÇÃO DE CRIANÇAS EM PERÍODO SENSÓRIO-MOTOR
}

\section{THE USE OF PERCUSSION INSTRUMENTS IN MUSIC EDUCATION OF CHILDREN IN THE SENSORIMOTOR PERIOD}

\author{
Eliana Cecilia Maggioni Guglielmetti Sulpício \\ Universidade de São Paulo \\ elianasulpicio@usp.br \\ Gabrielle Estabille Parreira \\ Universidade de São Paulo \\ gabrielleep@usp.br \\ Lígia Donizete dos Santos Pires \\ Universidade de São Paulo \\ ortrzpires@hotmail.com
}

\begin{abstract}
Resumo
Este artigo apresenta algumas considerações iniciais de uma pesquisa que vem sendo desenvolvida junto ao "Programa Ensinar com Pesquisa" do Departamento de Música da FFCLRP-USP. Este estudo se propõe a refletir sobre o uso de instrumentos de percussão com o propósito de estimular o desenvolvimento de crianças que se encontram no período sensório-motor. De acordo com Piaget, este período vai desde o nascimento até aproximadamente os dois anos de idade. Neste sentido, o objetivo desta pesquisa é investigar esta fase e propor atividades com instrumentos de percussão que possam estimular o desenvolvimento do bebê.
\end{abstract}


Palavras-chave: Percussão; coordenação-motora; Piaget; crianças.

\section{Introdução}

Piaget, um dos mais importantes nomes nas pesquisas de educação e pedagogia do século XX, através de observações, criou a teoria do desenvolvimento da inteligencia humana, mostrando que a inteligência se dá quando o organismo se adapta a novas situações, logo, quanto mais difícil a situação, mais inteligente o individuo poderá vir a ser. Desta maneira, pode-se dizer que a inteligência pode ser exercitada e aperfeiçoada. A teoria recebeu o nome de Epistemologia Genética e trata do estudo dos mecanismos do aumento do conhecimento; segundo Piaget, o comportamento é construído através da interação entre o meio e o indivíduo, portanto, não é inato (BELLO, 1995).

processo cognitivo é explicado por Piaget através do esquema (schema), que são estruturas cognitivas pelas quais os indivíduos intelectualmente se adaptam e organizam o meio. Através deste esquema a criança é capaz de receber novos estímulos, processá-los, identificá-los e modificá-los; dessa maneira ocorre o processo de assimilação, ou seja, a criança possui certo número de esquemas e a partir de um estímulo ela irá assimilá-lo a um esquema disponivel, assim ela é capaz de adaptar a nova experiência às estruturas cognitivas prévias.

O próximo processo, Piaget denominou de acomodação. Neste processo, não existe uma estrutura cognitiva que possa ser assimilada pela criança. Ela irá criar um novo esquema no qual possa encaixar o novo estímulo. Por fim acontece o processo de equilibração, quando a assimilação e a acomodação são bem sucedidas, garantindo assim uma interação eficiente entre criança e meio ambiente (TAFNER, 2008). 


\section{Fases do desenvolvimento}

Piaget divide o desenvolvimento humano, a partir do nascimento, em quatro estágios, de acordo com a maturação. Esses períodos acontecem com todos, porém a idade que eles ocorrem pode variar de acordo com o desenvolvimento cognitivo de cada criança e dos estímulos que acentuam estes processos. Segundo Lopes et al (2010), uma criança vai se desenvolver muito mais rápido e eficazmente se estimulada desde cedo. Estes periodos são: $1^{\circ}$ período: Sensório-motor, de zero a dois anos; $2^{\circ}$ período: Pré-operatório, de dois a sete anos; $3^{\circ}$ período: Operações concretas, de sete a onze ou doze anos e $4^{\circ}$ periodo: Operações formais, de 11 ou 12 anos em diante.

Para Piaget, mesmo antes do nascimento, o feto encontra-se em processo de desenvolvimento cognitivo, ou seja, o desenvolvimento do individuo inicia-se no perío do intrauterino (BELLO, 1995). Segundo llari (2005), algumas sensações sonoras são adquiridas ainda no útero materno. Os fetos estão constantemente expostos a sons internos e externos ao corpo da mãe durante a gestação, como o som do fluxo sanguíneo, as batidas do coração, o som dos movimentos intestinais, sua voz, uma música e outros ruídos (LINDNER, 1999). Os canais auditivos já estão formados desde o quinto mês de gravidez, o que faz com que quando o bebê nasça, já tenha uma memória auditiva de aproximadamente quatro meses, por isso, ele é capaz de reconhecer sua mãe pelo tom de sua voz.

Segundo llari (2002, p. 88) o bebé é considerado um ouvinte sofisticado, pois consegue notar sons agudos, sons graves, ritmos, timbres, etc.

Do terceiro trimestre de gravidez ao terceiro mês de vida pósnatal, os bebes preferem ouvir notas e sons graves (LECANUET et al., 2000), e escutam-nos com maior facilidade do que os sons agudos (UERNER a VANDENBOS, 1993, p. 624-626). Porém, com o passar do tempo, isso se reverte de maneira que, por volta dos 6 meses, os be- 
bês tenham maiores facilidades e prefiram ouvir sons agudos. Somente por volta dos dois anos de idade é que a audição dos bebês para sons agudos vai estar semelhante à de um adulto normal (UERNER e VANDENBOS, 1993, p. 624-626). Essa preferencia por sons agudos foi demonstrada por Olsho (1984) numa experiência realizada com bebês de 5 a 8 meses de idade. Em experiência análoga, Trainor e Zacharias (1998) demonstraram que os bebês preferem música vocal cantada no registro agudo à mesma música cantada em registro grave (ILARI, 2002, p. 85).

O bebê está sempre alerta a movimentos e sons que o cercam, atentando-se ainda mais quando a fala de sua mãe é dirigida a ele. A interação entre o bebê e a mãe faz com que o bebê se sinta seguro. Quando a mãe canta para seu filho, este canto torna-se uma importante ferramenta de comunicação entre ambos.

Estabelecida essa comunicação, que pode ser considerada inteiramente instintiva, constitui-se pouco a pouco uma brincadeira entre mãe e filho, criando assim, um laço afetivo. Os comportamentos e verbalizações de mães e crianças influenciam-se reciprocamente, caracterizando um cenário de troca mútua em que a criança é parte ativa e dinâmica nas interações, e a mãe o elemento da díade responsável pela criação de uma estrutura sócio interativa favorável à aprendizagem da linguagem. Desta forma, não importa a profundidade de conhecimento musical da mãe, pois ela, intuitivamente, estará interagindo com seu bebê, e reagindo às suas verbalizações. As interações e reações são extremamente importantes no desenvolvimento e no fortalecimento da relação mãe-filho. Sendo assim, a mãe estimula o bebê, e o bebê estimula a mãe, fortalecendo, desta forma, a identidade de um ao outro (Braz \& Salomão, 2002, apud FILIPAK e ILARI, 2005, p. 87). De acordo com Palhares (2009, p. 553), "ao nascer, o bebê interage com o seu meio produzindo diferentes tipos de sons, os quais comunicam o seu estado emocional e são diferentes conforme a sua idade." Parizzi (2006, p. 4 1), dividiu em três níveis a comunicação pré-verbal dos bebês. No primeiro nível, por volta dos dois meses de idade, o bebê 
é capaz de produzir e modular sons através das vogais, direcionada pela fala dos pais; no segundo nível, que se inicia por volta dos quatro meses de idade, o bebê passa a produzir algumas consoantes e brincar com sua voz, utilizando alturas, intensidades e timbres diferentes; nesta fase o bebe repete sons descobertos por acaso e ficam alegres com sua própria produção vocal; o terceiro nivel, caracterizado por "balbucios canônicos", ou seja, repetição de silabas como "mamama" ou "dadada", se inicia por volta dos sete meses de idade.

\section{A música a e o desenvolvimento da criança}

A música pode auxiliar o desenvolvimento humano em todas as fases da vida. $O$ mundo está repleto de expressões rítmicas, como as batidas do coração, a marcha de um caminhar, o "tic-tac" do relógio, o piscar dos olhos, um padrão de fala, dentre outros. Isso faz com que a criança necessite do desenvolvimento do senso rítmico desde cedo. Além deste ponto, a música traz consigo elementos de caráter social, como o despertar do lúdico e da curiosidade, a socialização, a capacidade de se expressar, o desenvolvimento da percepção do mundo. Segundo Ferres (1998), a música é uma grande aliada dos pais no ensino de regras comportamentais das crianças, colaborando para que este processo aconteça de uma forma mais natural e sem traumas. Dentro da faixa etária que abrange o período sensório-motor, podemos subdividir as idades das crianças de acordo com comportamentos especificos de cada fase. Crianças de zero a três meses possuem, em sua maioria, comportamentos reflexos inatos como o choro, reflexos de sucção e preensão palmar. Em crianças de três a seis meses, o comportamento específico dos pais elou cuidadores podem auxiliar seu desenvolvimento, e é importante que os estímulos musicais estejam presentes, tais como mostrar brinquedos como chocalhos, emitir sons diferentes estimulando a busca da fonte sonora pela criança, etc. Em crianças de seis aos doze meses há um maior desenvolvimento cognitivo e motor. Estímulos como produzir sons com chocalhos e guizos para que a criança pegue tais objetos, é uma das formas de auxiliar 
o desenvolvimento desta etapa. Oferecer objetos sonoros que possam ser empurrados e puxados, deixá-la rodeada de alguns instrumentos para que possa explorar o ambiente, são atividades que ajudam no desenvolvimento da percepção.

Crianças dos doze aos quinze meses estão começando a andar, e é importante que este novo aprendizado seja explorado. A utilização de instrumentos como chocalhos em forma de bola, que possa ser chutado, é uma interessante "ferramenta" que pode auxiliar essa nova atividade realizada pela criança. Nesta fase, a criança já tem coordenação para bater um objeto contra o outro, desta forma, pode-se utilizar instrumentos que possam ser percutidos uns aos outros, auxiliando desta forma na melhora da sua coordenação motora.

Por volta dos 18 meses a dois anos de idade a criança começa a desenvolver ainda mais sua coordenação motora, conseguindo movimentar pernas, braços, cintura e cabeça de acordo com o ritmo dos instrumentos. Com essa idade, a criança mantém o ritmo imitando um adulto, é capaz de formar frases e silabas sem sentindo e também participar de bandinhas ritmicas, desde que os movimentos sejam simples e as músicas contenham letras repetidas.

Entre os estudiosos que pesquisaram a relação da música com o desenvolvimento do corpo, destaca-se Émile-Jacques Dalcroze, que desenvolveu um estudo que ficou conhecido como Eurritmica, que significa "bom ritmo". Ele considera que através do movimento do corpo seja possivel vivenciar cada elemento da música. Para ele, o corpo humano é o primeiro instrumento musical e o mais importante para o desenvolvimento motor da criança (COULART, 2005). Para o autor, através de atividades corporais, a criança ou mesmo o adulto deve sentir a música por meio da escuta, aprimorando assim sua audição através de movimentos espontâneos que contribuem para o desenvolvendo de sua criatividade. Em seu método, Dalcroze mostra a importância do uso de brincadeiras, jogos ritmicos e musicais para treinar a audição (TEIXEIRA, 2012). 
Dalcroze se preocupava em tornar seus alunos pessoas melhores tanto na música como na vida:

Com a finalidade de suprir as necessidades de seus alunos na aprendizagem da música, Dalcroze indicava uma metodologia cuja vivência dos elementos musicais antecede a intelectualização de suas simbologias. Suas ideias refletiam sua preocupação com a formação global do aluno, incluindo o corpo, a alma e o espírito. Visava formar um ser melhor, mais sensivel, não somente para a música, mas para a vida (ENDLER e CAMPOS, 2007, p. 3).

Outro educador musical que trabalhou com o princípio do movimento do corpo, e que foi fortemente influenciado pelos estudos de Dalcroze, foi Carl Orff. Seu modo de ensinar baseava-se em atividades lúdicas como cantar, bater palmas, dançar e percutir objetos. Apesar de seu método estar voltado para crianças acima de dois anos de idade, e envolver atividades com pequenos teclados de percussão, improvisação, leitura e escrita musical, a base de seu trabalho, ou seja, - lúdico associado aos movimentos e ao som, pode ser adaptada para crianças que se encontram no periodo sensório-motor. Princípios similares ao de Dalcroze.

\section{Considerações finais}

Alguns instrumentos de percussão podem se tornar "ferramentas" interessantes e dinamizadoras do processo de desenvolvimento motor e cognitivo de crianças. Segundo Mársico (1982, apud Ferreira et al 2007, p. 11), "os instrumentos de percussão podem ser considerados como extensões dos instrumentos naturais de percussão - mãos, pés, dedos". Sendo assim, podem contribuir muito para a formação da criança.

Dentre estes instrumentos de percussão, pretendemos explorar e criar instrumentos que sejam mais apropriados ao desenvolvimento da 
criança nesta fase, levando em consideração que o material escolhido deverá sempre considerar a segurança da criança, não contendo pontas, material cortante, nem partes que se desgrudem ou saiam facilmente. Os materiais também têm que ser de fácil manuseio, leves e não possuirem sons estridentes, que possam irritar ou causar desconforto aos bebês.

Neste sentido, nossa pesquisa ainda se encontra em fase inicial, e na sequência, além de buscar maiores embasamentos teóricos, pretendemos desenvolver uma oficina de atividades práticas com os bebês e suas mães, de forma a podermos aplicar o estudo aqui desenvolvido.

\section{Referências}

BELLO, J. L. P. A teoria básica de Jean Piaget. Vitória, 1995.

Encontro Anual da ABEM e Congresso Regional da ISME, 16, 2007, Mato Grosso do Sul. A Rítmica de Dalcroze e a Teoria das Inteligências Múltiplas de Gardner: uma Relação Possivel. Resumo. Goiânia, 2007.

FERES, J. S. M. Bebê Música e Movimento: Orientação Para Musicalização Infantil. Jundiaí: 1998.

FERREIRA, D. L. A. et al: A influência da linguagem musical na educação infantil. Disponivel em http://www.histedbr.fe.unicamp.br/acer_histedbr/jornada/jornada7/_CT4\%2OPDF/A\%2OINFLU\%CANCIA\%20DA\%20 LINCUACEM\%2OMUSICAL\%2ONA\%20EDUCA\%C7\%C3O\%2OINFANTII.pdf (acessado em 21.05 .2014 ).

A Contribuição da Música no Desenvolvimento da Psicomotricidade. Revista Eletrônica Saberes da Educação, São Roque, v. 3, n. 1, 2012 . 
COULART, D. Metodologias de ensino da música. Porto Alegre, 2005. Disponivel em http://www.google.com.br/url? sa=tErct=$j \varepsilon q=\varepsilon e s r c=s \& f r m=1$ \&source =web $\& c d=3 \& v e d=0 C D A Q F j A C \& u r \mid=h t-$ tp\%3A\%2F\%2Fpead.faced.ufrgs.br\%2Fsites\%2Fpublico\%2Feixo3\%2Fmusica\%2Fmusica_planejamento_____2F( 12 2)\%2520M\%25E9todos\%2520de\%2520Ensino\%2520da\%2520M\%25FAsica\%2FMETODOLOCIAS\%2520ENSINO\%2520M\%25DASICA\%2520.pptEei=kNcMVJ2yBofioASVqICABwEusg=AFQjCNE6qmBclrNcXALZupS7USg5jMz-JQEsig2=de-pDW2NUhl4egVTtCV-5wEbvm=bv.7 4649129,d.cWc (acessado em 13.05.20 14).

ILARI, B.; FILIPAK, R. Mães e Bebês: vivência e linguagem musical. Música Hodie, [S.I.], v. 5, n. 1, fev. 2008. ISSN 23 17-6776. Disponivel em http:// revistas.ufg.br/index.php/musica/article/view/2656/11548 (acessado em 12.05.20|4).

ILARI, B. A música e o desenvolvimento da mente no início da vida: investigação, fatos e mitos. Revista eletrônica de musicologia, Curitiba, v. 9, n. 1, out. 2005. Disponivel em http://www.rem.ufpr.br/_REM/REMv9-1/ ilari.html (acessado em 20.05.20 l4).

Bebês também entendem de música: a percepção e a cognição musical no primeiro ano de vida. Revista da ABEM, Porto Alegre, v. 7, 83-90, set. 2002. Disponivel em http://abemeducacaomusical.com. br/revistas/revistaabem/index.php/revistaabem/article/view/435 (acessado em 21.05 .2014 ).

LOPES, R. M. F. et al: Desenvolvimento cognitivo e motor de crianças de zero a quinze meses: um estudo de revisão. 20 10. Disponivel em http:// www.psicologia.pt/artigos/textos/A0529.pdf (acessado em 10.08.20 l 4).

MONTEIRO, N. C. C. R. A música ajuda no desenvolvimento do bebê desde a sua formação no ventre. Disponivel em http://bebesemusica. blogspot.com.br (acessado em 20.08.20 l4). 
PALHARES, T. H. As vocalizações de dois bebês entre 5 e 18 meses de idade. In : SIMCAM, 5., 2009. Goiânia. Anais... Mato Grosso: ABCM, 2009. p. 552-555.

PARIZZI, M. B. O canto espontâneo da criança de zero a seis anos: dos balbucios às canções transcendentes. Revista da ABEM, Porto Alegre, v. 15, 39-48, set. 2006. Disponivel em http://www.abemeducacaomusical.com.br/revistas/revistaabem/index.php/revistaabem/article/view/300 (acessado em 19.12.2015).

PEIXOTO, V.; JARDIM, A. Carl Orff, in Cadernos de Educação Musical, FUNARTE, $n^{\circ} 1,1980$.

TAFNER, M. A construção do conhecimento segundo Piaget. Disponivel em http://www.cerebromente.org.br/nO8/mente/construtivismo/construtivismo.htm (acessado em 17.05.2014).

TEIXEIRA, M. I. S. M. Método Dalcroze: Jogos Rítmicos Musicais, 2012. Disponivel em http://scavonemusical.blogspot.com.br (acessado em 12.05.20 14).

TERRA, M. R. O desenvolvimento humano na teoria de Piaget. Disponivel em http://www.unicamp.br/iel/site/alunos/publicacoes/textos/d00005. htm (acessado em 12.05.2014). 